\title{
BMJ Open Cross-sectional associations of neighbourhood socioeconomic disadvantage and greenness with accelerometer-measured leisure-time physical activity in a cohort of ageing workers
}

\author{
Jaana I Halonen (10 ,1,2 Anna Pulakka, ${ }^{3,4,5}$ Jaana Pentti, ${ }^{2,3,4}$ Minna Kallio, ${ }^{6}$ \\ Sofia Koskela, ${ }^{7}$ Mika Kivimäki, ${ }^{2,8}$ Ichiro Kawachi, ${ }^{9}$ Jussi Vahtera (D) ,3,4 \\ Sari Stenholm (iD) ${ }^{3,4}$
}

To cite: Halonen JI, Pulakka A, Pentti J, et al. Crosssectional associations of neighbourhood socioeconomic disadvantage and greenness with accelerometermeasured leisure-time physical activity in a cohort of ageing workers. BMJ Open 2020;10:e038673. doi:10.1136/ bmjopen-2020-038673

- Prepublication history and additional material for this paper are available online. To view these files, please visit the journal online (http://dx.doi org/10.1136/bmjopen-2020038673).

Received 19 March 2020

Revised 17 June 2020 Accepted 03 July 2020

Check for updates

(c) Author(s) (or their employer(s)) 2020. Re-use permitted under CC BY-NC. No commercial re-use. See rights and permissions. Published by BMJ.

For numbered affiliations see end of article.

Correspondence to

Dr Sari Stenholm;

sari.stenholm@utu.fi

\section{ABSTRACT}

Objective Neighbourhood characteristics may affect the level of physical activity (PA) of the residents. Few studies have examined the combined effects of distinctive neighbourhood characteristics on PA using objective data or differentiated between activity during working or non-working days. We examined the associations of socioeconomic disadvantage and greenness with accelerometer-measured leisure-time PA during working and non-working days.

Design Cross-sectional study.

Setting Finnish Retirement and Aging (FIREA) study. Participants 708 workers (604 women, mean age 62.4 ranging from 58 to 64 years,) participating in the FIREA study who provided PA measurement data for at least 1 working and non-working day.

Primary and secondary outcomes PA was measured with wrist-worn accelerometer on average of 4 working and 2 non-working days. Outcomes were total PA, light PA (LPA) and moderate-to-vigorous PA (MVPA). These measurements were linked to data on neighbourhood socioeconomic disadvantage and greenness within the home neighbourhood $(750 \times 750 \mathrm{~m})$. Generalised linear models were adjusted for possible confounders.

Results On non-working days, higher neighbourhood disadvantage associated with lower levels of total PA ( $p$ value $=0.07$ ) and higher level of neighbourhood greenness associated with higher level of total PA ( $p$ value $=0.04$ ). Neighbourhood disadvantage and greenness had an interaction ( $p$ value $=0.02$ ); in areas of low disadvantage higher greenness did not associate with the level of total PA. However, in areas of high disadvantage, 2 SD higher greenness associated with $46 \mathrm{~min} /$ day $(95 \% \mathrm{Cl} 8.4$ to $85)$ higher total PA. Slightly stronger interaction was observed for LPA $(p=0.03)$ than for the MVPA $(p=0.09)$. During working days, there were no associations between neighbourhood characteristics and leisure-time total PA. Conclusions of the disadvantaged neighbourhoods, those characterised by high levels of greenness seem to associate with higher levels of leisure-time PA during
Strengths and limitations of this study

- Physical activity (PA) was measured objectively with wrist-worn accelerometers rather than self-reports allowing separate analysis for light, moderate-tovigorous and total PA.

- Data on working days enabled us to separately assess leisure-time PA on working days versus nonworking days.

- Neighbourhood disadvantage and greenness were independently assessed, allowing us to check the interactive effect of these two dimensions in relation to leisure-time PA.

- The study population included predominately female ageing workers, so the generalisability of the findings to other populations needs to be confirmed in future studies.

Cross-sectional study design limits causal inference.

non-working days. These findings suggest that efforts to add greenness to socioeconomically disadvantaged neighbourhoods might reduce inequalities in PA.

\section{BACKGROUND}

Physical activity (PA) is a modifiable health behaviour with high relevance in the prevention of major chronic conditions (eg, cardiovascular disease and diabetes). ${ }^{1}$ Several factors such as poor health status, ${ }^{2}$ higher age, ${ }^{2}$ obesity, ${ }^{3}$ low socioeconomic position in childhood $^{4}$ and adulthood ${ }^{6}$ have been linked to lower leisure-time PA. In addition, socioeconomic, ${ }^{7}$ built ${ }^{289}$ and natural characteristics ${ }^{1011}$ of residential neighbourhoods have shown to be associated with differences in PA levels. 
Most evidence regarding the association of residential neighbourhoods and level of PA to date relies on selfreported PA measurements. ${ }^{12}{ }^{13}$ Such data are not ideal and may either underestimate or over-estimate the associations due to inaccuracies in self-reporting. ${ }^{14}$ More recent studies have used accelerometer-measured PA, but the findings on associations with neighbourhood characteristics have been mixed. ${ }^{15-18}$ One study found built environment and socioeconomic neighbourhood characteristics to be associated with accelerometer-measured PA in people aged $\geq 69$ years such that the built characteristics (eg, density of shops and services) had a smaller role in PA than neighbourhood-level income. ${ }^{16}$ In two studies, the amount of green space was not associated with PA, ${ }^{16} 19$ but in a third study, among younger adults, higher availability of green areas was linked to higher PA levels. ${ }^{20}$ Yet another study of 14 cities observed an association between number of parks within $500 \mathrm{~m}$ buffer around home (ie, an indicator of greenness) and PA. ${ }^{18}$ At least one earlier study sought to distinguish associations of neighbourhood walkability and PA from those of neighbourhood-level income and PA, that is, the interaction of the two neighbourhood variables. In their main analysis, minutes of walking for transportation were higher in high versus low walkability neighbourhoods. When stratifying by neighbourhood income level, this association remained and was slightly stronger in high-income versus low-income neighbourhoods after controlling for neighbourhood preferences. ${ }^{21}$ However, studies addressing the question whether there is an interaction between neighbourhood socioeconomic disadvantage and natural characteristics in relation to objectively measured PA are scarce. The interaction between socioeconomic disadvantage and greenness is of particular interest as green areas have been associated with several health benefits, including $\mathrm{PA},{ }^{10}{ }^{11}$ while the increasing rate of urbanisation ${ }^{22}$ is leading to changes in land use. It is therefore essential to provide more detailed information about the role of greenness for urban planners for the basis of just and effective desicions. ${ }^{23}$

Some inconsistences in prior research may be because they reported accelerometer-measured overall PA across all measurement days rather than focusing separately on leisure-time PA during working and non-working days. This is an important caveat, because residential environments are more likely associated with leisure-time PA of working adults since people are expected to spend leisure time in these environments. One study among workingaged adults examined associations between neighbourhood characteristics and PA by day of the week and time of the day. ${ }^{24}$ However, that study did not provide information on the work status of the participants and thus the differences in associations on working and non-working days could not be examined.

To address some of the gaps in prior evidence, we examined independent and joint associations of socioeconomic and natural characteristics of residential neighbourhood with leisure-time light PA (LPA) and moderate-tovigorous PA (MVPA), that is, total PA, separating working and non-working days, and using objective measures of the exposures and outcomes.

\section{METHODS}

\section{Study population}

The Finnish Retirement and Aging (FIREA) study is an ongoing longitudinal cohort study of older adults in Finland. The population eligible for the FIREA included all public-sector employees working in 2012 in one of the 27 municipalities in Southwest Finland, or in nine selected cities of five hospital districts around Finland, whose retirement date was between 2014 and 2019. ${ }^{25}$ The survey cohort includes 6679 participants who have responded to at least one of the FIREA questionnaires. All participants provided written informed consent.

We used data from the FIREA activity substudy including 938 participants who were still working at the baseline of the substudy. ${ }^{26}$ Of them, we excluded six participants whose accelerometer-assessed total PA measurements had technical errors, 29 who had no valid PA measurements for any day, 156 who did not have information on 1 working and 1 non-working days and 39 who had no linkage to both objective measures of neighbourhood characteristics based on coordinates of their home address. While many studies have used a minimum of 3-4 valid days of PA measurement, ${ }^{1618}$ some have used lower cutoffs. ${ }^{1724} \mathrm{We}$ included an analytical sample that consisted of 708 participants with minimum of 1 day of valid data for working and non-working day to obtain adequate power for the statistical analyses. Valid data were defined as 10 hours of more wake wear time.

\section{Neighbourhood characteristics}

Neighbourhoods were characterised by socioeconomic disadvantage and greenness, which were available on a $250 \times 250 \mathrm{~m}$ map grid that covers the whole country. For sensitivity analyses, we included a binary variable for urban areas (inner and outer urban areas vs not) whose definition was based on the urban-rural classification of the Finnish Environment Institute. ${ }^{27}$

\section{Socioeconomic disadvantage}

We calculated a standardised index for neighbourhood socioeconomic disadvantage like in previous studies. ${ }^{28} 29$ We used median household income (coded as additive inverse), low educational attainment (percentage of people over 18 years old with low education) and unemployment rate (unemployed people belonging to the labour force/total labour force) from each map square. For each of the three variables, we derived a standardised $z$ score (national mean $=0, \mathrm{SD}=1$ ). A total disadvantage score was then calculated by taking the mean value across all $z$ scores; the mean of the score in the study population was -0.15 (range -2.13 to 3.86 ), with a higher score indicating a higher disadvantage. The information for the map grid was based on the total population living within each square at the time of data collection. ${ }^{30}$ Here we used 
population registers from 2012 by Statistics Finland. For the analyses, we defined a neighbourhood as nine $250 \times 250$ $\mathrm{m}$ map squares, that is, the square where the participant's residence was located and the eight surrounding squares, resulting in $750 \times 750 \mathrm{~m}$ neighbourhoods. This slightly larger area is likely more relevant than the small $250 \times 250$ $\mathrm{m}$ square when examining leisure-time PA and is more comparable to prior studies that have used $0.5 \mathrm{~km}$ buffers based on road distance. ${ }^{10} 18$

\section{Greenness}

The degree of greenness in the neighbourhood was calculated as Normalised Difference Vegetation Index (NDVI) that can get values ranging from -1 to 1 where values below zero represent cloud, snow and water surfaces, and values above zero represent land surfaces. Here, the index was derived from a satellite image composite using Google Earth Engine. ${ }^{31}$ The composite was a median of cloud-free $30 \times 30 \mathrm{~m}$ resolution Landsat 5 Thematic Matter surface reflectance images selected between June and August, in 2009 and 2010. These data were also processed to fit the grid of Statistics Finland, and mean NDVI was calculated for each $250 \times 250 \mathrm{~m}$ map square. For the analyses, we removed areas covered by water and recoded these areas as NDVI $=0$. This was made to prevent negative values for underestimating the greenness values of the neighbourhoods like in prior studies. ${ }^{32}{ }^{33}$ After this, we calculated mean percentage of NDVI, later referred to as greenness, for each square. As with the other measures, $750 \times 750 \mathrm{~m}$ areas defined neighbourhoods.

\section{Measurement of PA}

We used triaxial ActiGraph accelerometers, models wActiSleep-BT and wGT3X-BT (ActiGraph, Pensacola, Florida, USA) to measure PA over 7 consecutive days and six consecutive nights. Between September 2014 and January 2017, the devices were mailed to the participants along with instructions to wear the device on their non-dominant wrist throughout the measurement period, including waterbased activities such as swimming, but to remove it for sauna. They were asked to record in a diary their bedtime, waking time, information about working or non-working day and, for working days, time of the beginning and end of each work shift when they wore the device.

We used R-package GGIR ${ }^{34}$ V.1.8.0 to analyse raw acceleration data from the wrist-worn accelerometers in $\mathrm{R}$ statistical software, V.3.5.1 (R Foundation for Statistical Computing, Vienna, Austria, https://cran.r-project.org/). The R-package GGIR script that we used is shown in the online supplementary material. The GGIR method ${ }^{35-37}$ included (1) autocalibration according to the local gravity, (2) detection of sustained abnormally high values and non-wear time and (3) calculation of the average magnitude of dynamic acceleration expressed as Euclidean Norm Minus One (ENMO, as mg, milligravitational units where $g=9.81 \mathrm{~m} / \mathrm{s}^{2}$ ) over $5 \mathrm{~s}$ epochs with negative values rounded to zero. Sleep time was detected and excluded from the activity measurements based on the algorithm of the GGIR package, which was guided by the information from the diaries. ${ }^{38}$ Non-wear time was based on 15 min blocks, based on the characteristics of the $60 \mathrm{~min}$ window centred at these 15 min blocks. A block was classified as non-wear time if SD of the $60 \mathrm{~min}$ window was less than $13.0 \mathrm{mg}$ for at least two out of the three axes or if the value range, for at least two out of three axes, was less than $50 \mathrm{mg} .{ }^{35} 37$

Days with less than 10 hours of accelerometer wake wear time were excluded. Based on the diary markings, we further restricted the activity measurements to time periods including only leisure time: leisure time during working days (ie, wake time outside working hours) or all wake time on non-working days. We defined LPA using a threshold of $30 \mathrm{mg}^{39}$ and MVPA by a threshold of $100.6 \mathrm{mg} .{ }^{40}$ Total PA was calculated as a sum of LPA and MVPA.

\section{Covariates}

The participants' age, sex and occupational title codes in 2012 were obtained from the register of pension insurance institute for the municipal sector in Finland. We categorised occupations into three classes by the International Standard Classification of Occupations (ISCO) ${ }^{41}$ : high=ISCO classes 1-2 (eg, managers and professionals), intermediate $=\mathrm{ISCO}$ classes 3-4 (eg, technicians and clerks) and low=ISCO classes 5-9 (eg, catering personnel and manual workers).

For additional analyses, we further used body mass index (BMI) and chronic disease, which are shown to associate with both neighbourhood characteristics ${ }^{42-44}$ and PA. ${ }^{23}$ These variables were not included in the main analysis as they may also act as effect modifiers in associations between neighbourhood characteristics and PA. BMI was calculated from self-reported weight and height and categorised into normal weight $(<25.0 \mathrm{~kg} /$ $\mathrm{m}^{2}$, including five persons whose BMI was below $18.5 \mathrm{~kg} /$ $\mathrm{m}^{2}$ ), overweight $\left(25\right.$ to $\left.<30 \mathrm{~kg} / \mathrm{m}^{2}\right)$ and obese $(\geq 30 \mathrm{~kg} /$ $\left.\mathrm{m}^{2}\right) .{ }^{45}$ Chronic disease was based on a question: 'Has your doctor ever told that you have or have had any of the following diseases?'. Following diseases were included in the chronic disease variable: angina pectoris, myocardial infarction, stroke, intermittent claudication, chronic bronchitis, osteoarthritis, osteoporosis, sciatica, fibromyalgia, rheumatoid arthritis, depression, other mental disorder, migraine and malignant neoplasm. For the analyses, a chronic disease variable was categorised as having $0,1, \geq 2$ diseases, as in a prior study. ${ }^{25}$

\section{Statistical analyses}

We used generalised linear models (Generalized Estimating Equation, GENMOD procedure in SAS with normal distribution) for assessing the associations of neighbourhood disadvantage and greenness with objectively measured leisure-time total PA, LPA and MVPA on working and non-working days ( $p$ values for interaction for workday $\times$ disadvantage $\times$ greenness were 0.02 for total PA, 0.06 for LPA and 0.03 for MVPA). Assumptions for generalised linear models include that data are 
Table 1 Descriptive statistics of the study population $(\mathrm{n}=708)$ neighbourhood variables and physical activity

\begin{tabular}{|c|c|c|}
\hline Variable & n (\%) & Mean (SD) \\
\hline \multicolumn{3}{|l|}{ Sex (missing -) } \\
\hline Women & $604(85)$ & \\
\hline Men & $104(15)$ & \\
\hline \multicolumn{3}{|l|}{ Occupational status (-) } \\
\hline High & $278(39)$ & \\
\hline Intermediate & $200(29)$ & \\
\hline Low & $230(32)$ & \\
\hline \multicolumn{3}{|l|}{ Body mass index (24) } \\
\hline$<25$ & $292(43)$ & \\
\hline $25-29.9$ & $262(38)$ & \\
\hline$\geq 30$ & $130(19)$ & \\
\hline \multicolumn{3}{|l|}{ Chronic disease (21) } \\
\hline 0 & $155(22)$ & \\
\hline 1 & $245(36)$ & \\
\hline$\geq 2$ & 287 (42) & \\
\hline Urban area $(-)$ & $631(89)$ & \\
\hline Age & 708 & $62.4(1.2)$ \\
\hline \multicolumn{3}{|l|}{ Residential neighbourhood* } \\
\hline Disadvantage index & 708 & $-0.15(0.6)$ \\
\hline Greenness† & 708 & $0.53(0.1)$ \\
\hline \multicolumn{3}{|l|}{ Mean MVPA (min/day) } \\
\hline Leisure time on working days & 708 & $39(23)$ \\
\hline Non-working days & 708 & $53(39)$ \\
\hline \multicolumn{3}{|l|}{ Mean LPA (min/day) } \\
\hline Leisure time on working days & 708 & $139(55)$ \\
\hline Non-working days & 708 & $236(98)$ \\
\hline \multicolumn{3}{|l|}{ Mean total PA (min/day) } \\
\hline Leisure time on working days & 708 & $169(65)$ \\
\hline Non-working days & 708 & $290(114)$ \\
\hline \multicolumn{3}{|l|}{$\begin{array}{l}\text { Mean number of valid } \\
\text { measurement days }\end{array}$} \\
\hline Leisure time on working days & 708 & $4.4(1.0)$ \\
\hline Non-working days & 708 & $2.5(0.98)$ \\
\hline \multicolumn{3}{|l|}{$\begin{array}{l}\text { Mean minutes of wake wear } \\
\text { time }\end{array}$} \\
\hline Leisure-time on working days & 708 & $538(87)$ \\
\hline Non-working days & 708 & $903(69)$ \\
\hline
\end{tabular}

*Participant's residential $250 \times$ square and the eight surrounding $250 \times 250 \mathrm{~m}$ squares.

†Normalised Difference Vegetation Index (range 0-1). LPA, light physical activity; MVPA, moderate-to-vigorousphysical-activity; Total PA, light and moderate-to-vigorousphysical-activity.

independently distributed, that is, cases are independent. However, the GENMOD procedure can model the correlation between observations. The dependent variable does not need to be normally distributed, but it typically assumes a distribution from an exponential family (eg, binomial, Poisson, multinomial or normal). Distributions of the exposures and outcomes are shown in online supplementary figure 1 . We adjusted models for age, sex, occupational status and accelerometer wear time, for which no missing data existed. The associations were determined as change (95\% confidence limits, CL) in daily minutes of PA per 1 SD increase in the neighbourhood characteristics. To examine the interactions between neighbourhood disadvantage and greenness in relation to leisure-time PA, we added the term 'disadvantagexgreenness' to models including their main effects and the covariates. Equation for the main analysis model is the following:

Total $\mathrm{PA}=\mathrm{a}+\mathrm{b} 1 *$ sex $+\mathrm{b} 2 *$ age $+\mathrm{b} 3 *$ occupational status 1 $+\mathrm{b} 4 *$ occupational status $2+\mathrm{b} 5 *$ wear time $+\mathrm{b} 8 *$ neighbourhood disadvantage $+\mathrm{b} 9 *$ greenness $+\mathrm{b} 10 *$ neighbourhood disadvantage *greenness, where a=intercept, bi=regression coefficient

To illustrate the findings from interaction models, the results are presented as the associations on the greenness continuums (from $-1 \mathrm{SD}$ to $+1 \mathrm{SD}$ ) with the levels of PA at three levels on the neighbourhood disadvantage $(-1 \mathrm{SD}$, mean and $+1 \mathrm{SD})$. To further test the significance of the three slopes of the disadvantagexgreenness interaction, we used a simple slope analysis. The test of each coefficient is a t-test formed by the ratio of the coefficient to its standard error $(\mathrm{t}=\mathrm{b}(\mathrm{atZ}) / \mathrm{SE}(\mathrm{atZ})) .{ }^{46}$ We also examined whether there were interactions of sex or occupational status with the neighbourhood characteristics in relation to leisure-time PA. This was done because individuals with varying sociodemographic indicators may have different patterns of use-of-time. ${ }^{47}$ We observed no such interactions ( $p$ values for interactions $0.14-0.40$ ), thus results are reported for the total study population only. As an additional analysis, we ran models adjusted for BMI and number of chronic disease, where those with missing data for chronic disease were excluded. Finally, as sensitivity analyses, we ran the models by only including participants who lived in urban areas to rule out biases related to characteristics specific to rural areas where high level of greenness is likely (total PA only). All statistical analyses were performed using SAS V.9.4 (SAS Institute).

\section{Patient and public involvement}

PA behaviour is a universal topic, not limited to specific patient group, thus no patient or public representatives were involved in designing or implementation of the study. The main research findings of the FIREA study will be published in peer-reviewed scientific journals and presented in national and international events and conferences as well as disseminated to public via press releases, social media and seminars.

\section{RESULTS}

Of the participants, $85 \%$ were women and mean age was 62.4 (range from 58 to 64 ) years. The participants were 
Table 2 Leisure-time total physical activity by 1 SD increase in neighbourhood disadvantage and greenness

\begin{tabular}{|c|c|c|c|c|c|c|}
\hline \multirow[b]{2}{*}{ Exposure } & \multicolumn{3}{|l|}{ Model 1* } & \multicolumn{3}{|l|}{ Model 2† } \\
\hline & min/day & $95 \% \mathrm{Cl}$ & $P$ value & $\min /$ day & $95 \% \mathrm{Cl}$ & $P$ value \\
\hline \multicolumn{7}{|l|}{ Non-working days } \\
\hline Greenness & 8.1 & -0.2 to 16.4 & 0.06 & 10.4 & 2.0 to 18.9 & 0.02 \\
\hline Disadvantagexgreenness & & & & 11.6 & 2.1 to 21.2 & 0.02 \\
\hline Disadvantage & -0.3 & -4.6 to 4.0 & 0.89 & -0.83 & -5.3 to 3.6 & 0.71 \\
\hline Greenness & 3.8 & -0.5 to 8.0 & 0.09 & 4.2 & -0.2 to 8.6 & 0.06 \\
\hline Disadvantagexgreenness & & & & 2.2 & -2.8 to 7.1 & 0.39 \\
\hline
\end{tabular}

${ }^{*}$ Model 1 adjusted for age, sex, occupational status and accelerometer wear time.

†Model 2 adjusted for age, sex, occupational status and accelerometer wear time and interaction of neighbourhood disadvantage and greenness.

evenly distributed into the three occupational statuses (table 1). Mean number of valid days of PA measurements was $4.4(\mathrm{SD}=1.0)$ on working days and $2.5(\mathrm{SD}=0.98)$ on non-working days. Pearson correlation coefficient was $\mathrm{r}=-0.10 \quad(\mathrm{p}=0.01)$ for neighbourhood disadvantage and index of greenness.

During non-working days, 1 SD increase in neighbourhood socioeconomic disadvantage was associated with a $6.7 \mathrm{~min}$, although non-significant, decrease in leisuretime total PA while 1 SD increase in greenness associated with $8.1 \mathrm{~min}$ increase in total PA (table 2). However, the neighbourhood disadvantage-PA association depended on the level of greenness (test of interaction, p value 0.02 ). The beta coefficient for the disadvantage $\times$ greenness interaction term was 11.6 (95\% CL 2.1 to 21.2), indicating a stronger association between higher disadvantage and higher total PA with higher levels of greenness. Figure 1 shows that in areas of low disadvantage $(-1 \mathrm{SD})$, higher greenness did not associate with the level of total PA ( $p$ value for slope $0.811 / 1 \mathrm{SD}$ ), while in the areas of high disadvantage $(+1 \mathrm{SD}, \mathrm{p}$ value for slope $0.002 / 1 \mathrm{SD})$, the interaction indicates 46 (95\% CI 8.4 to 85 ) min more PA when greenness was $2 \mathrm{SD}$ higher (from $-1 \mathrm{SD}$ to $+1 \mathrm{SD}$ ) when compared with low disadvantage areas. Findings on non-working days of the main analysis for both LPA and MVPA were in the same direction but only that for greenness and LPA reached statistical significance $(65 \mathrm{~min} /$ day, 95\% CI 7.4 to 122) (table 3). Interactions between disadvantage and greenness on non-working days were borderline significant in the models for MVPA ( $p$ value 0.09 ) and significant for LPA ( $p$ value 0.03 ) (table 3 ).

The results pointed to the same direction when modelling differences in leisure-time total PA during working days but associations were not statistically significant $p$ values ranging from 0.08 to 0.75 (table 2). No interactions between neighbourhood disadvantage and greenness

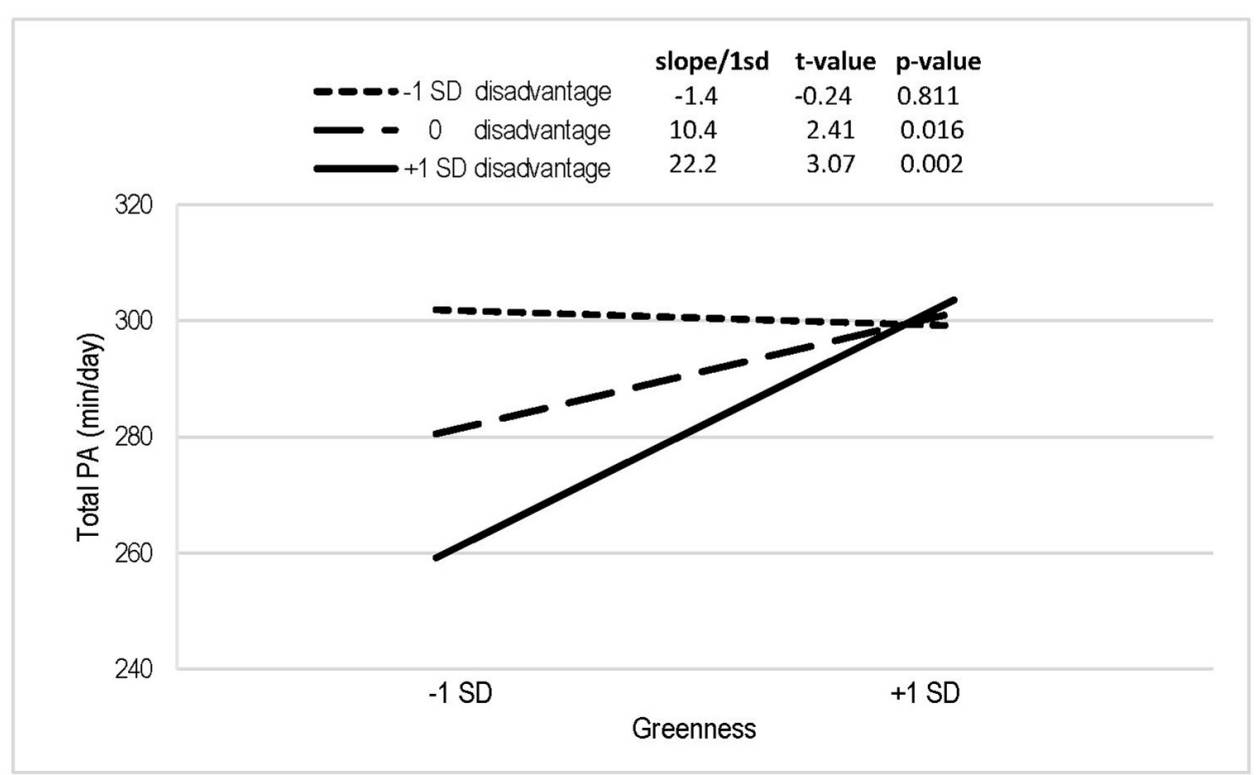

Figure 1 Minutes of leisure-time total PA on non-working days by disadvantage and greenness. Models adjusted for age, sex, occupational status and accelerometer wear time. PA, physical activity. P value for interaction 0.02 . 
Table 3 Leisure-time light and moderate-to-vigorous physical activity by 1 SD increase in neighbourhood disadvantage and greenness

\begin{tabular}{|c|c|c|c|c|c|c|}
\hline \multirow[b]{2}{*}{ Exposure } & \multicolumn{3}{|l|}{ Model 1* } & \multicolumn{3}{|l|}{ Model 2† } \\
\hline & $\min /$ day & $95 \% \mathrm{Cl}$ & $P$ value & $\min /$ day & $95 \% \mathrm{Cl}$ & $P$ value \\
\hline \multicolumn{7}{|l|}{ LPA } \\
\hline Disadvantage & -3.9 & -10.9 to 3.1 & 0.28 & -6.0 & -13.2 to 1.3 & 0.11 \\
\hline Greenness & 7.5 & 0.4 to 14.5 & 0.04 & 9.3 & 2.0 to 16.5 & 0.01 \\
\hline Disadvantage & 0.52 & -3.1 to 4.1 & 0.77 & 0.1 & -3.6 to 3.9 & 0.95 \\
\hline Greenness & 4.7 & 1.1 to 8.3 & 0.01 & 5.1 & 1.4 to 8.8 & 0.01 \\
\hline Disadvantagexgreenness & & & & 1.6 & -2.5 to 5.8 & 0.44 \\
\hline \multicolumn{7}{|l|}{ MVPA } \\
\hline Disadvantagexgreenness & & & & 2.9 & -0.5 to 6.3 & 0.09 \\
\hline \multicolumn{7}{|l|}{ Working days } \\
\hline Disadvantage & -0.83 & -2.5 to 0.8 & 0.33 & -1.0 & -2.7 to 0.8 & 0.28 \\
\hline Greenness & -0.97 & -2.6 to 0.7 & 0.26 & -0.9 & -2.6 to 0.9 & 0.33 \\
\hline Disadvantagexgreenness & & & & 0.5 & -1.4 to 2.5 & 0.59 \\
\hline
\end{tabular}

*Model 1 adjusted for age, sex, occupational status and accelerometer wear time.

†Model 2 adjusted for age, sex, occupational status and accelerometer wear time and interaction of neighbourhood disadvantage and greenness.

were observed for working days ( $\mathrm{p}$ values 0.39 for total PA, 0.59 for MVPA and 0.44 for LPA). Additional adjustments for BMI and chronic disease did not markedly change the effect estimates (online supplementary tables 1 and 2). In the sensitivity analyses, restricting the study population to those living in urban areas $(n=631$ with mean age of 62.4), the findings were largely similar, the association between increasing disadvantage and lower level of PA being stronger on non-working $(-10.8 \mathrm{~min} /$ day, $95 \%$ CI -20.3 to -1.33$)$ than working $(-1.96 \mathrm{~min} /$ day, $95 \%$ CI -6.88 to 2.96 ) days in the urban areas (table 4 ).

\section{DISCUSSION}

Using objective high-resolution data on neighbourhood characteristics and accelerometer measured leisure-time PA in a cohort of ageing workers, we observed that the association between neighbourhood socioeconomic

Table 4 Leisure-time total (light and moderate-to-vigorous) physical activity by $1 \mathrm{SD}$ increase in neighbourhood disadvantage and greenness in urban areas

\begin{tabular}{|c|c|c|c|c|c|c|}
\hline \multirow[b]{2}{*}{ Exposure } & \multicolumn{3}{|l|}{ Model 1* } & \multicolumn{3}{|c|}{ Model 2† } \\
\hline & min/day & $95 \% \mathrm{Cl}$ & $P$ value & min/day & $95 \% \mathrm{Cl}$ & $P$ value \\
\hline \multicolumn{7}{|l|}{ Non-working days } \\
\hline Greenness & 5.4 & -3.56 to 14.3 & 0.24 & 7.7 & -1.7 to 17.0 & 0.11 \\
\hline Disadvantagexgreenness & & & & 9.2 & -2.6 to 21.0 & 0.12 \\
\hline Disadvantage & -1.9 & -6.9 to 3.0 & 0.44 & -2.0 & -6.9 to 3.0 & 0.44 \\
\hline Greenness & 2.6 & -2.0 to 7.2 & 0.27 & 2.8 & -2.0 to 7.7 & 0.25 \\
\hline Disadvantagexgreenness & & & & 1.0 & -5.1 to 7.1 & 0.75 \\
\hline
\end{tabular}

*Model 1 adjusted for age, sex, occupational status and accelerometer wear time.

†Model 2 adjusted for age, sex, occupational status and accelerometer wear time and interaction of neighbourhood disadvantage and greenness. 
disadvantage and total PA and LPA depended on the level of greenness in the neighbourhood. In areas of high disadvantage, 2 SD higher greenness associated with 46 more total PA minutes on non-working days. In areas of low disadvantage, greater greenness did not associate with total PA.

To the best of our knowledge, this is the first study to examine associations of socioeconomic and natural neighbourhood characteristics with total PA separately during leisure time on working and non-working days. Prior studies have shown increased PA among lower SES populations, mostly due to PA associated with walking as participants are more likely to use active transportation for commuting. ${ }^{48-50}$ Commuting does not explain our findings since there were no associations on working days, but our results emphasise the importance of focusing on non-working days when PA may take place in residential neighbourhoods. One prior study has assessed associations between neighbourhood characteristics and PA for different times of the day reporting stronger associations for times when adults were expected to be in their neighbourhood and awake (on weekdays before 9 am or after $5 \mathrm{pm}$ and on weekends). ${ }^{24}$ These findings are in line with ours, although in that study no information on the participants' working schedules was available. Our results are in agreement also with the findings indicating that an individual's level of PA on working days is strongly related to a person's occupation ${ }^{26}$ and mode of commuting. ${ }^{51}$

Findings for greenness, when assessed individually, are in line with the common hypothesis that greenness would increase PA. ${ }^{10}$ Moreover, we observed an interaction for neighbourhood socioeconomic disadvantage with greenness in relation to PA on non-working days. In the better-off areas, increase in greenness was not associated with the level of PA; however, in the areas of high disadvantage increase in greenness associated with a notable increase in PA. If these findings are replicated in longitudinal settings supporting causal inference, they suggest that creating green areas in the disadvantaged areas could increase PA of the residents, and subsequently, induce public health benefits. The observed interactions also suggest that exposure to multiple (vs single) poor neighbourhood characteristics is likely to be more harmful for the residents' activity behaviours. Though one prior study has reported that lower and higher income groups had similar levels of leisure-time walking in high-walkability neighbourhoods, ${ }^{21}$ there is a need for more research on the joint effects of poor neighbourhood characteristics on health behaviours and health. These studies are particularly important regarding greenness as green spaces can also play role in the adaptation to climate change.

Some limitations need to be considered when interpreting our findings. The study population was female dominated and late middle aged, thus limiting the generalisability of the findings to other population groups. However, the findings are important in the context of ageing workers, because chronic conditions increase with age while PA has beneficial effects on the prevention and management of several diseases. The used wristworn accelerometers have some inherent weaknesses, including not being able to capture all the activities, such as bicycling or weight training. They neither provide information about the context of the activity. Differences between accelerometer placement and analysis methods hinder comparison of results from wrist-worn accelerometers to accelerometers worn on other locations, such as hip. ${ }^{52}$ The measure for greenness was based on data from 2009 to 2010, whereas the PA measurements took place in 2012. The time gap between the measurements may have caused some exposure misclassification although greenness is likely to vary rather slowly over time in urban environments where majority of the participants lived. In addition, the greenness measure did not distinguish by type or quality of green that may be relevant for PA. ${ }^{53}$ A further limitation is that the data were cross-sectional and thus we are unable to conclude whether the observed associations were exogenous, that is, unrelated to the persons' decision to move to an area due to his/her PA preferences.

The main strengths of this study include the highresolution objectively measured exposure and outcome variables, which increases the validity of the measures. Additionally, the associations were independent of important confounders such as individual socioeconomic status, and we could distinguish associations for leisuretime PA on working and non-working days.

\section{CONCLUSIONS}

We observed that neighbourhood socioeconomic disadvantage, although non-significantly, and greenness were related to the level of PA on non-working days but not on leisure-time PA on working days. The results indicate that higher neighbourhood disadvantage is associated with lower levels of PA, whereas higher greenness is associated with higher levels of PA. Importantly, we also observed that the association between higher greenness and higher level of PA was stronger in the more disadvantaged areas. Thus, efforts to add greenness to socioeconomically disadvantaged neighbourhoods might reduce inequalities in PA. Additionally, these findings suggest that differentiating between working and non-working days as well as interactions between neighbourhood characteristics should be considered in future neighbourhood research.

\section{Author affiliations}

${ }^{1}$ Health Security, Finnish Institute for Health and Welfare, Helsinki, Finland ${ }^{2}$ Faculty of Medicine, University of Helsinki, Helsinki, Finland

${ }^{3}$ Centre for Population Health Research, University of Turku, Turku, Finland ${ }^{4}$ Department of Public Health, University of Turku, Turku, Finland

${ }^{5}$ Public Health Solutions, Finnish Institute for Health and Welfare, Helsinki, Finland

${ }^{6}$ Geoinformatics Services, Finnish Environment Institute, Helsinki, Finland ${ }^{7}$ Department of Geography and Geology, University of Turku, Turku, Finland ${ }^{8}$ Department of Epidemiology and Public Health, University College London, London, UK

${ }^{9}$ Department of Society Human Development, Harvard University T H Chan School of Public Health, Boston, Massachusetts, USA 
Twitter Jaana I Halonen @jaana_halonen

Acknowledgements The authors want to thank the FIREA participants for their willingness to participate in the study and the FIREA study staff members for their contribution in the data collection. In addition, the authors wish to acknowledge CSC_-IT Center for Science, Finland, for computational resources and support.

Contributors $\mathrm{JIH}, \mathrm{AP}, \mathrm{JP}, \mathrm{JV}, \mathrm{IK}$ and SS conceived and designed the experiments, AP did the accelerometer data handling, JIH analysed the data, AP, MK, SK and SS contributed materials and/or analysis tools. MK and SS contributed to the funding of the study. All authors were involved in writing the paper and approved the submitted version.

Funding This work was supported by Academy of Finland (projects 286294, 294 154 and 319246 for SS) and Ministry of Education and Culture of Finland. MKi was supported by NordForsk, the Academy of Finland (331492), and Helsinki Institute of Life Science. AP was supported by Päivikki and Sakari Sohlberg Foundation. The funders had no role in the design of the study or collection, analysis, and interpretation of data or in writing the manuscript.

Competing interests None declared.

Patient consent for publication Obtained.

Ethics approval The study protocol was approved by the Ethics Committee of Hospital District of Southwest Finland.

Provenance and peer review Not commissioned; externally peer reviewed.

Data availability statement Data are available upon reasonable request. Anonymised partial datasets of the Finnish Retirement and Aging Study are available by application with bona fide researchers with an established scientific record and bona fide organisations. For more information, please contact Prof. Sari Stenholm sari.stenholm[at]utu.fi.

Open access This is an open access article distributed in accordance with the Creative Commons Attribution Non Commercial (CC BY-NC 4.0) license, which permits others to distribute, remix, adapt, build upon this work non-commercially, and license their derivative works on different terms, provided the original work is properly cited, appropriate credit is given, any changes made indicated, and the use is non-commercial. See: http://creativecommons.org/licenses/by-nc/4.0/.

\section{ORCID iDs}

Jaana I Halonen http://orcid.org/0000-0003-1142-0388

Jussi Vahtera http://orcid.org/0000-0002-6036-061X

Sari Stenholm http://orcid.org/0000-0001-7560-0930

\section{REFERENCES}

1 Wahid A, Manek N, Nichols M, et al. Quantifying the association between physical activity and cardiovascular disease and diabetes: a systematic review and meta-analysis. J Am Heart Assoc 2016;5:JAHA.115.002495.

2 Choi J, Lee M, Lee J-K, et al. Correlates associated with participation in physical activity among adults: a systematic review of reviews and update. BMC Public Health 2017;17:356.

3 Trost SG, Owen N, Bauman AE, et al. Correlates of adults participation in physical activity: review and update. Med Sci Sports Exerc 2002;34:1996-2001.

4 Elhakeem A, Cooper R, Bann D, et al. Childhood socioeconomic position and adult leisure-time physical activity: a systematic review. Int J Behav Nutr Phys Act 2015;12:92.

5 Cheval B, Sieber S, Guessous I, et al. Effect of early- and Adult-Life socioeconomic circumstances on physical inactivity. Med Sci Sports Exerc 2018;50:476-85

6 Beenackers MA, Kamphuis CBM, Giskes K, et al. Socioeconomic inequalities in occupational, leisure-time, and transport related physical activity among European adults: a systematic review. Int J Behav Nutr Phys Act 2012;9:116.

7 Xiao Q, Keadle SK, Berrigan D, et al. A prospective investigation of neighborhood socioeconomic deprivation and physical activity and sedentary behavior in older adults. Prev Med 2018;111:14-20.

8 Van Cauwenberg J, De Bourdeaudhuij I, De Meester F, et al. Relationship between the physical environment and physical activity in older adults: a systematic review. Health Place 2011;17:458-69.

9 Witten K, Blakely T, Bagheri N, et al. Neighborhood built environment and transport and leisure physical activity: findings using objective exposure and outcome measures in New Zealand. Environ Health Perspect 2012;120:971-7.
10 Fong KC, Hart JE, James P. A review of epidemiologic studies on Greenness and health: updated literature through 2017. Curr Envir Health Rpt 2018;5:77-87.

11 Klompmaker JO, Hoek G, Bloemsma LD, et al. Green space definition affects associations of green space with overweight and physical activity. Environ Res 2018;160:531-40.

$12 \mathrm{Li} \mathrm{F}$, Fisher KJ, Brownson RC, et al. Multilevel modelling of built environment characteristics related to neighbourhood walking activity in older adults. J Epidemiol Community Health 2005;59:558-64.

13 Van Cauwenberg J, Nathan A, Barnett A, et al. Relationships between neighbourhood physical environmental attributes and older adults' leisure-time physical activity: a systematic review and metaanalysis. Sports Med 2018;48:1635-60.

14 Prince SA, Adamo KB, Hamel ME, et al. A comparison of direct versus self-report measures for assessing physical activity in adults: a systematic review. Int J Behav Nutr Phys Act 2008:5:56.

15 Bancroft C, Joshi S, Rundle A, et al. Association of proximity and density of Parks and objectively measured physical activity in the United States: a systematic review. Soc Sci Med 2015;138:22-30.

16 Hawkesworth S, Silverwood RJ, Armstrong B, et al. Investigating associations between the built environment and physical activity among older people in 20 UK towns. J Epidemiol Community Health 2018;72:121-31.

17 Frank LD, Schmid TL, Sallis JF, et al. Linking objectively measured physical activity with objectively measured urban form: findings from SMARTRAQ. Am J Prev Med 2005;28:117-25.

18 Sallis JF, Cerin E, Conway TL, et al. Physical activity in relation to urban environments in 14 cities worldwide: a cross-sectional study. Lancet 2016;387:2207-17.

19 Ord K, Mitchell R, Pearce J. Is level of neighbourhood green space associated with physical activity in green space? Int J Behav Nutr Phys Act 2013;10:127.

20 Astell-Burt T, Feng X, Kolt GS. Green space is associated with walking and moderate-to-vigorous physical activity (mvpA) in middleto-older-aged adults: findings from 203883 Australians in the 45 and up study. Br J Sports Med 2014;48:404-6.

21 Sallis JF, Saelens BE, Frank LD, et al. Neighborhood built environment and income: examining multiple health outcomes. Soc Sci Med 2009;68:1285-93.

22 United Nations DoEaSA, Population Division. World urbanization prospects: the 2018 revision (ST/ESA/SER.A/420. New York,United Nations, 2019.

23 Hunter RF, Cleland C, Cleary A, et al. Environmental, health, wellbeing, social and equity effects of urban green space interventions: a meta-narrative evidence synthesis. Environ Int 2019;130:104923.

24 Cerin E, Mitáš J, Cain KL, et al. Do associations between objectivelyassessed physical activity and neighbourhood environment attributes vary by time of the day and day of the week? IPEN adult study. Int $J$ Behav Nutr Phys Act 2017:14:34.

25 Leskinen T, Pulakka A, Heinonen OJ, et al. Changes in nonoccupational sedentary behaviours across the retirement transition: the Finnish retirement and aging (FIREA) study. J Epidemiol Community Health 2018;72:695-701.

26 Pulakka A, Leskinen T, Koster A, et al. Daily physical activity patterns among aging workers: the Finnish retirement and aging study (FIREA). Occup Environ Med 2019;76:33-9.

27 Finnish Environment Institute (SYKE). Urban-Rural classification 2013, 2014. Available: http://www.syke.fi/en-US/Research Development/Built environment and land use/More_accurate information_available_abou [Accessed 12 Feb 2015].

28 Halonen JI, Pulakka A, Stenholm S, et al. Change in neighborhood disadvantage and change in smoking behaviors in adults: a longitudinal, within-individual study. Epidemiology 2016:27:803-9.

29 Halonen Jl, Kivimäki M, Pentti J, et al. Quantifying neighbourhood socioeconomic effects in clustering of behaviour-related risk factors: a multilevel analysis. PLoS One 2012;7:e32937.

30 Statistics Finland. Grid Database, 2013. Available: http://www. tilastokeskus.fi/tup/ruututietokanta/index_en.html [Accessed 1 Jan 2016].

31 Gorelick N, Hancher M, Dixon M, et al. Google earth engine: planetary-scale geospatial analysis for everyone. Remote Sens Environ 2017;202:18-27.

32 Markevych I, Standl M, Sugiri D, et al. Residential greenness and blood lipids in children: a longitudinal analysis in GINIplus and LISAplus. Environ Res 2016;151:168-73.

33 Fuertes E, Markevych I, Bowatte G, et al. Residential greenness is differentially associated with childhood allergic rhinitis 
and aeroallergen sensitization in seven birth cohorts. Allergy 2016;71:1461-71.

34 Migueles JH, Rowlands AV, Huber F, et al. GGIR: a research Community-Driven open source $\mathrm{R}$ package for generating physical activity and sleep outcomes from Multi-Day RAW Accelerometer data. J Meas Phys Behav 2019;2:188-96.

35 Sabia S, van Hees VT, Shipley MJ, et al. Association between questionnaire- and accelerometer-assessed physical activity: the role of sociodemographic factors. Am J Epidemiol 2014;179:781-90.

36 van Hees VT, Fang Z, Langford J, et al. Autocalibration of accelerometer data for free-living physical activity assessment using local gravity and temperature: an evaluation on four continents. $J$ Appl Physiol 2014;117:738-44.

37 van Hees VT, Gorzelniak L, Dean León EC, et al. Separating movement and gravity components in an acceleration signal and implications for the assessment of human daily physical activity. PLoS One 2013;8:e61691.

38 van Hees VT, Sabia S, Anderson KN, et al. A novel, open access method to assess sleep duration using a Wrist-Worn Accelerometer. PLoS One 2015;10:e0142533.

39 Rowlands AV, Mirkes EM, Yates T, et al. Accelerometer-assessed physical activity in epidemiology: are monitors equivalent? Med Sci Sports Exerc 2018:50:257-65

40 Hildebrand M, VAN Hees VT, Hansen BH, et al. Age group comparability of raw accelerometer output from wrist- and hip-worn monitors. Med Sci Sports Exerc 2014;46:1816-24.

41 Statistics Finland. Classification of occupations 2001, 2002. Available: http://www.stat.fi/meta/luokitukset/ammatti/001-2001/ index_en.html [Accessed 13 Dec 2016].

42 Halonen JI, Kivimäki M, Pentti J, et al. Green and blue areas as predictors of overweight and obesity in an 8-year follow-up study. Obesity 2014;22:1910-7.

43 Halonen JI, Stenholm S, Pentti J, et al. Childhood psychosocial adversity and adult neighborhood disadvantage as predictors of cardiovascular disease: a cohort study. Circulation 2015;132:371-9.

44 Kimbro RT, Sharp G, Denney JT. Home and away: area socioeconomic disadvantage and obesity risk. Health Place 2017;44:94-102.

45 WHO. Obesity and overweight: World Health organization, 2010. Available: http://www.who.int/dietphysicalactivity/publications/facts/ obesity/en/ [Accessed 24 Nov 2010].

46 Aiken LS, West SG. Multiple regression: testing and interpreting interactions. Newbury Park, London: Sage, 1991.

47 Welk GJ, Kim Y. Context of physical activity in a representative sample of adults. Med Sci Sports Exerc 2015;47:2102-10.

48 Rachele JN, Kavanagh AM, Badland H, et al. Associations between individual socioeconomic position, neighbourhood disadvantage and transport mode: baseline results from the habitat multilevel study. J Epidemiol Community Health 2015;69:1217-23.

49 Olsen JR, Mitchell R, Mutrie N, et al. Population levels of, and inequalities in, active travel: a national, cross-sectional study of adults in Scotland. Prev Med Rep 2017;8:129-34.

50 Molina-García J, Menescardi C, Estevan I, et al. Neighborhood built environment and socioeconomic status are associated with active Commuting and sedentary behavior, but not with leisure-time physical activity, in university students. Int J Environ Res Public Health 2019;16:3176.

51 Batista Ferrer H, Cooper A, Audrey S. Associations of mode of travel to work with physical activity, and individual, interpersonal, organisational, and environmental characteristics. J Transp Health 2018;9:45-55.

52 Kerr J, Marinac CR, Ellis K, et al. Comparison of Accelerometry methods for estimating physical activity. Med Sci Sports Exerc 2017;49:617-24.

53 Picavet HSJ, Milder I, Kruize H, et al. Greener living environment healthier people?: exploring green space, physical activity and health in the Doetinchem cohort study. Prev Med 2016;89:7-14. 